Meta-Analysis

\title{
The prognostic significance of high/positive expression of cyclin B1 in patients with three common digestive cancers: a systematic review and meta-analysis
}

\author{
Yong Wen ${ }^{1, *}$, Lei Cao, ${ }^{2, *}$, Wen-Ping Lian ${ }^{3}$ and Guo-Xia Li ${ }^{4}$ \\ ${ }^{1}$ Chinese Medicine Department, Southwest Medical University Affiliated Hospital, Luzhou 646000, China \\ ${ }^{2}$ Department of Pediatrics, Gansu Provincial Maternity and Child Care Hospital, Lanzhou 730000, China \\ ${ }^{3}$ Department of Clinical Laboratory, The Third People's Hospital of He'nan Province, Zhengzhou 450000, China \\ ${ }^{4}$ Department of Pathology, Shanghai Minhang District Central Hospital, Shanghai 201199, China \\ *These authors contributed equally to this work
}

Correspondence to: Guo-Xia Li, email: agitation@yeah.net

Keywords: cyclin B1, gastric cancer, colorectal cancer, esophageal cancer, prognosis

Received: February 08, $2017 \quad$ Accepted: September 08, 2017

Published: September 26, 2017

Copyright: Wen et al. This is an open-access article distributed under the terms of the Creative Commons Attribution License 3.0 (CC BY 3.0), which permits unrestricted use, distribution, and reproduction in any medium, provided the original author and source are credited.

\section{ABSTRACT}

Recently, several studies have reported that the expression of cyclin B1 may be associated with the prognosis of cancer. Nevertheless, their conclusions were still controversial. The present was designed to analyze and evaluate the prognostic role of cyclin B1 expression in patients with digestive cancer. PubMed, Embase, Cochrane Library and Web of Science were searched to January, 2017. Pooled odds ratio (OR) with $95 \%$ confidence intervals (CIs) were estimated. For the pooled OR estimates of OS, we performed subgroup analysis. Besides, sensitivity analysis was performed to examine the stability of the combined results. All statistical analyses were performed using standard statistical procedures provided in RevMan 5.2. A total of 12 studies ( $N=2080$ participants) were included for this meta-analysis. The positive/high expression of cyclin B1 had an obvious association with both 3-year overall survival (OR 0.21, 95\% CI 0.12-0.37; $P<0.00001$ ) and 5-year overall survival (OR 0.20 , 95\% CI 0.12-0.34; $P<0.00001$ ) in esophageal cancer, and 5 -year overall survival of colorectal cancer (OR 2.01, 95\% CI 1.32-3.08; $P=0.001$ ). This meta-analysis indicated that positive/high expression of cyclin B1 may have a close association with worse survival in patients with esophageal cancer, but better prognosis in patients with colorectal cancer.

\section{INTRODUCTION}

Digestive malignancies, especially gastric cancer, colorectal cancer and esophageal cancer, are rampant in several countries around the world. Colorectal cancer, as one of the most common digestive malignancies, is occupying the fourth in diagnosed cancer and in the second place of leading death of patients with cancer in the United States [1]. In 2015, it is estimated that about five thousands of people will die of CRC [1,2]. Colorectal cancer was reported the third most frequently found malignancy, with male incidence of percentage 12.3 and female $13.1 \%$ [3, 4]. Additionally, in spite of the early detection with endoscopic screening in North America, $\mathrm{CRC}$ is in the third places in most common cause of cancer-related deaths, including both of patients who underwent operation or not [5].

At present, several advances have been made in the treatment approaches, imaging techniques and staging procedures. However, in spite of advanced instruments like electronic gastroscope and electron colonoscopy which could early detect digestive lesion, there were still approximately $20 \%$ of patients finding to be metastatic when they were diagnosed $[6,7]$. Therefore, further appropriate prognostic bio-markers are required to predict the prognosis of patients who underwent operation and their clinical status 
of tumor, then to guide the doctor to give more attention to patient who may experience poor prognosis.

In recent years, increasing number of studies have reported that the expression of cyclin B1 may be correlated with the poor outcome of patients with various cancers, including breast carcinoma [8], prostatic cancer [9], pancreatic malignancy [10], lung carcinoma [11], laryngeal cancer [12] as well as hepatocellular cancer [13], gastric cancer (GC) [14-17], colorectal cancer [18-21] and esophageal cancer (EC) [22-25]. However, the conclusions of these studies was still incongruent, for some studies drawing unsupported conclusions [18, 19]. Therefore, the present meta-analysis on the basis of relevant studies were conducted to analyze and assess the prognostic value and clinical significance of high or positive expression of cyclin B1, as well as its association with characteristics, in patients with three main digestive cancers, including gastric cancer, colorectal cancer and esophageal cancer.

\section{RESULTS}

\section{Included studies and characteristics}

After 34 studies were excluded according to our including criteria, eventually a total of 12 articles (2080 patients) were included for analysis and evaluation, of which 11 articles [14-20, 22-25] including 1971 patients were included for analyzing the correlation of positive/ high expression of cyclin B1 and OS, 9 studies [15-17, 19, 21-25] including 1253 participants for analyzing the correlation between cyclin B1 and clinicopathological features (Figure 1). The excluding reasons were as follows: 32 studies for lack of available data; 1 study [26] for the definition of positive/high expression did not meet our including criteria; 1 study [27] was just a review article with no available data. Of the included studies, six were conducted in Japan, three in China, each one in Brazil, Germany and Korea. The sample sizes ranged from 23 to 482 patients. Each four studies were about gastric, colorectal and esophageal cancer. Patients in nine studies were treated with surgery, two treated with adjuvant therapy like chemotherapy, radiotherapy or chemoradiotherapy, apart from surgery (Table 1).

\section{The prognostic value of positive/high expression of cyclin B1}

\section{The correlation between cyclin B1 expression and 3-year OS}

A total of 9 studies [16-20, 22-25] were included to analyze the relationship of positive/high cyclin B1 expression with 3-year overall survival in patients with digestive cancer. The pooled results showed no significance for positive/high expression of cyclin B1

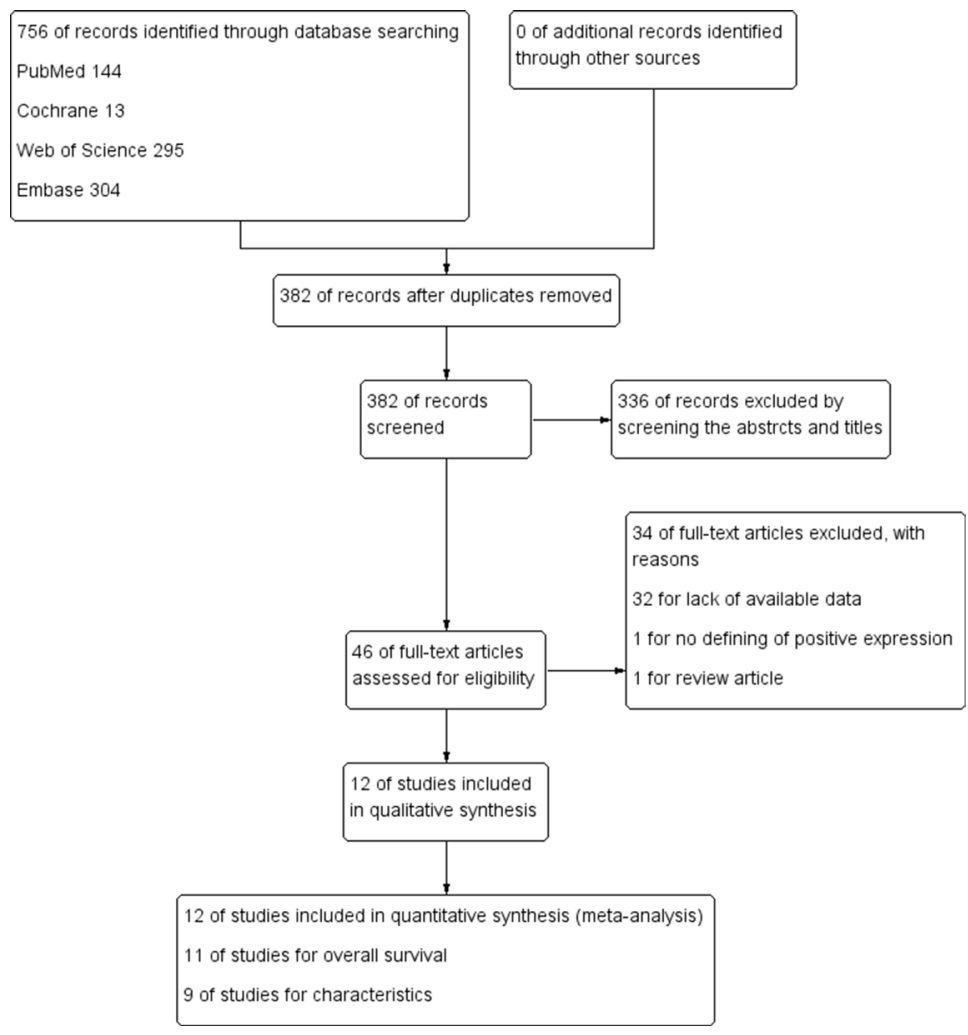

Figure 1: Flow diagram following the PRISMA template of the search strategy for expression of cyclin B1 in patients with cancer. 
Table 1: The characteristics of included studies

\begin{tabular}{|c|c|c|c|c|c|c|c|c|c|c|}
\hline Studies & Country & $\begin{array}{l}\text { No. of } \\
\text { Patients }\end{array}$ & $\begin{array}{l}\text { Tumor } \\
\text { Location }\end{array}$ & Treatment & FT (month) & $\begin{array}{l}\text { No. of Cyclin } \\
\text { B1 (+/-) }\end{array}$ & $\begin{array}{l}\text { Definition of } \\
\text { positive/high } \\
\text { expression }\end{array}$ & $\begin{array}{l}\text { Clinical } \\
\text { stage }\end{array}$ & $P$ value & $\begin{array}{l}\text { NOS } \\
\text { score }\end{array}$ \\
\hline Begnami et al. 2010 & Brazil & 482 & $\mathrm{GC}$ & Surgery & $\begin{array}{l}28.3 \\
(0.6-108.6)\end{array}$ & $229 / 231$ & $\begin{array}{l}\text { IHC stained } \\
\text { cytoplasm of } \\
\text { the tumor cell } \\
>10 \%\end{array}$ & NR & - & 6 \\
\hline Fang et al. 2015 & China & 150 & $\mathrm{CRC}$ & Surgery & NR & $88 / 62$ & $\begin{array}{l}\text { expression } \\
\text { ratio }>3.33\end{array}$ & I-IV & NR & 7 \\
\hline Grabsch et al. 2004 & Germany & 342 & $\mathrm{CRC}$ & $\begin{array}{l}\text { Surgery, CT, } \\
\text { RT or CRT }\end{array}$ & $\begin{array}{l}50.4 \\
(5-136.8)\end{array}$ & $261 / 69$ & $\begin{array}{l}\text { IHC } \\
\text { cytoplasmic } \\
\text { or nuclear } \\
\text { staining > } \\
10 \%\end{array}$ & I-IV & 0.5377 & 8 \\
\hline Huang et al. 2014 & China & 105 & $\mathrm{EC}$ & Surgery & NR & $28 / 17$ & $\begin{array}{l}\text { IHC staining } \\
\text { intensity } \\
\text { and cell } \\
\text { positive } \\
\text { rate score } \\
5-6 / 7 \text {,for } \\
++/+++\end{array}$ & I-III & 0.01 & 6 \\
\hline Kim et al. 2007 & Korea & 23 & $\mathrm{GC}$ & NR & $\begin{array}{l}68 \\
(3-108)\end{array}$ & $20 / 3$ & $\begin{array}{l}\text { IHC stained } \\
\text { tumor cell } \\
>5 \%\end{array}$ & I-IV & NR & 6 \\
\hline Korenaga et al. 2002 & Japan & 109 & $\mathrm{CRC}$ & Surgery & NR & $62 / 47$ & $\begin{array}{l}\text { IHC stained } \\
\text { either the } \\
\text { nucleus or } \\
\text { cytoplasm }\end{array}$ & NR & - & 6 \\
\hline Li JQ et al. 2003 & Japan & 194 & $\mathrm{CRC}$ & Surgery & NR & $68 / 75$ & $\begin{array}{l}\text { IHC } \\
\text { cytoplasmic } \\
\text { or nuclear } \\
\text { staining } \geq \\
4.6 \%\end{array}$ & I-IV & 0.119 & 8 \\
\hline Li YZ et al. 2009 & China & 336 & $\mathrm{GC}$ & Surgery & 45.4 & $222 / 114$ & $\begin{array}{l}\text { IHC } \\
\text { cytoplasmic } \\
\text { or nuclear } \\
\text { staining > } \\
10 \%\end{array}$ & I-IV & $<0.05$ & 7 \\
\hline Murakami et al. 1999 & Japan & 87 & $\mathrm{EC}$ & Surgery, CT & NR & $63 / 24$ & $\begin{array}{l}\text { IHC } \\
\text { cytoplasmic } \\
\text { staining }>5 \%\end{array}$ & I-IV & $>0.05$ & 6 \\
\hline Nozoe et al. 2002 & Japan & 120 & $\mathrm{EC}$ & Surgery & NR & $68 / 52$ & $\begin{array}{l}\text { IHC nuclear } \\
\text { and/or } \\
\text { cytoplasmic } \\
\text { staining > } \\
10 \%\end{array}$ & I-III & 0.177 & 7 \\
\hline Takeno et al. 2002 & Japan & 71 & $\mathrm{EC}$ & Surgery & NR & $35 / 36$ & $\begin{array}{l}\text { IHC staining } \\
>20 \%\end{array}$ & I-IV & $\begin{array}{l}< \\
0.0001\end{array}$ & 7 \\
\hline Yasuda et al. 2002 & Japan & 61 & $\mathrm{GC}$ & Surgery & 25.8 & $32 / 29$ & $\begin{array}{l}\text { IHC } \\
\text { cytoplasmic } \\
\text { staining > } \\
10 \%\end{array}$ & I-IV & 0.02 & 8 \\
\hline
\end{tabular}

CRC, colorectal cancer; EC, esophageal cancer; GC, gastric cancer; FT, follow-up time (median and range); CT, chemotherapy; RT, radiotherapy; CRT, chemo-radiotherapy; NOS, Newcastle-Ottawa Scale; IHC, immunohistochemistry; NR, not report.

predicting the 3-year overall survival of patients(OR 0.70 ; 95\% CI 0.33-1.51; $P=0.36$ ) (Figure 2).

\section{The correlation between cyclin B1 expression and} 5-year OS

Ten studies reported the association between positive/high expression of cyclin B1 and 5-year OS, of which four were about patients with esophageal cancer [22-25], four about gastric cancer [14-17] and two about colorectal cancer $[18,19]$. The combined result indicated that the high/positive expression of cyclin B1did not significant correlate with 5-year OS of digestive cancer patients (OR 0.56, 95\% CI 0.30-1.06; $P=0.07$ ) (Figure 3). 
The correlation between cyclin B1 expression and 3-year OS of EC, GC and CRC

Considering no significance in overall types of the three digestive cancers, we performed subgroup analysis according to gastric carcinoma (GC), colorectal carcinoma (CRC) and esophageal carcinoma (EC). The positive/high expression of cyclin B1 had an obvious association with 3 -year OS in patients with esophageal cancer according to the pooled results (OR $0.21,95 \%$ CI $0.12-0.37 ; P<$ 0.00001 ) (Figure 4). It revealed that esophageal cancer patients with positive/high expression of cyclin B1 had worse prognosis. However, no significant association between cyclin B1 and prognosis of patients with gastric cancer and colorectal cancer was found in our analysis.

\section{The correlation between cyclin $B 1$ expression and} 5-year OS of EC, GC and CRC

Likewise, we also estimated the correlation between cyclin B1 expression and 5-year OS of esophageal carcinoma (EC), gastric carcinoma (GC) and colorectal carcinoma (CRC) by subgroup analysis. We used fixed effect models because of no significant heterogeneity between studies. Our results showed statistically significant correlation between positive/high expression of cyclin B1 and 5-year OS of patients with EC and CRC, with the pooled OR being 0.20 [95\% CI 0.12-0.34; $P<0.00001$ ] and 2.01 [95\% CI 1.32-3.08; $P=0.001$ ], respectively (Figures 5 and 6). However, interestingly, patients with positive/high expression of cyclin B1 had worse prognosis in patients with esophageal carcinoma, but better prognosis in patients with colorectal carcinoma. No significant association between cyclin B1 and prognosis of patients with gastric cancer was found in our analysis.

\section{The correlation between Cyclin B1 expression and clinicopathologic features}

In order to explicate the point if the expression of cyclin B1 was correlated with clinical characteristics of patients, we explored whether Age, Gender, Size of tumor, Blood vessel invasion, Histologic type, Pathologic T, Pathologic N, Distant metastasis, Lymphatic vessel invasion and Clinical stage were correlated with high expression of cyclin B1. The results indicated significant association between positive/high cyclin B1 expression and Size of tumor (OR 0.60, 95\% CI 0.38, 0.93; $P=0.02$ ) and Distant metastasis (OR 0.30, 95\% CI 0.13, $0.71 ; P=$

\begin{tabular}{|c|c|c|c|c|c|}
\hline \multirow[b]{2}{*}{ Study or Subqroup } & \multicolumn{2}{|c|}{ Cyclin B1 (+) } & \multicolumn{2}{|c|}{ Cyclin B1 (-) } & \multirow[b]{2}{*}{ Weight } \\
\hline & Events & Total & Events & Total & \\
\hline Fang et al. 2015 & 68 & 88 & 40 & 62 & $13.6 \%$ \\
\hline Grabsch et al. 2004 & 208 & 261 & 52 & 69 & $14.0 \%$ \\
\hline Huang et al. 2014 & 19 & 28 & 16 & 17 & $6.9 \%$ \\
\hline Kim et al. 2007 & 18 & 20 & 1 & 3 & $5.0 \%$ \\
\hline Li JQ et al. 2003 & 62 & 68 & 67 & 75 & $11.6 \%$ \\
\hline Murakami et al. 1999 & 16 & 63 & 14 & 24 & $12.3 \%$ \\
\hline Nozoe et al. 2002 & 42 & 68 & 44 & 52 & $12.7 \%$ \\
\hline Takeno et al. 2002 & 10 & 35 & 27 & 36 & $11.9 \%$ \\
\hline Yasuda et al. 2002 & 14 & 32 & 9 & 29 & $11.9 \%$ \\
\hline Total $(95 \% \mathrm{CI})$ & & 663 & & 367 & $100.0 \%$ \\
\hline Total events & 457 & & 270 & & \\
\hline $\begin{array}{l}\text { Heterogeneity: } \mathrm{Tau}^{2}= \\
\text { Test for overall effect: }\end{array}$ & $\begin{array}{l}\text { 10; } \mathrm{Chi}^{2}= \\
0.91(\mathrm{P}=\end{array}$ & $\begin{array}{l}3.10, \mathrm{df} \\
.36)\end{array}$ & $=8(\mathrm{P}<0$ & 000 & $\left.\right|^{2}=80 \%$ \\
\hline
\end{tabular}

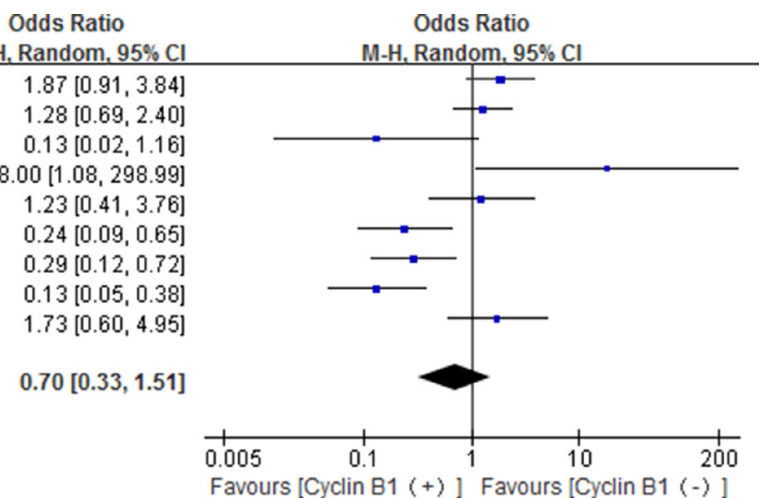

Figure 2: Forest plot for the association between positive/high expression of cyclin B1 and 3-year overall survival (OS) of overall types of cancer.

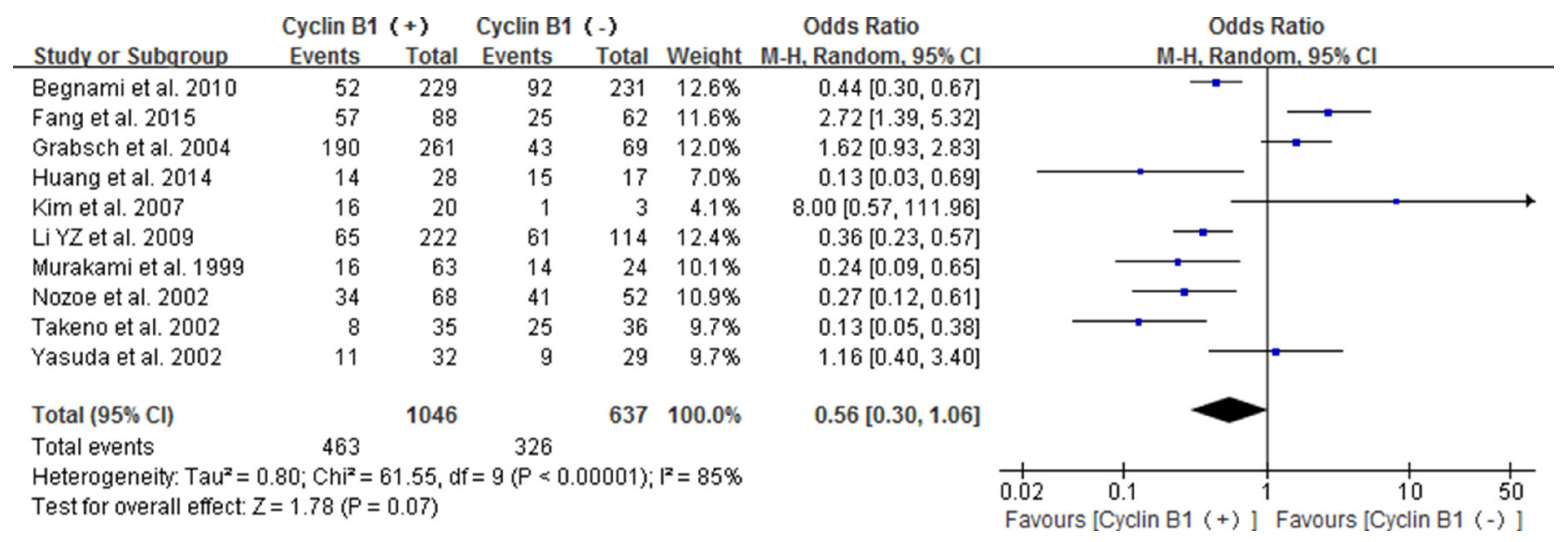

Figure 3: Forest plot for the association between positive/high expression of cyclin B1 and 5-year overall survival (OS) of overall types of cancer. 
0.006), using fixed-effect models. However, no significant association in other characteristics was found (Table 2).

\section{Subgroup, sensitivity analysis and publication bias}

Subgroup analysis was conducted to find the prognostic effects of positive/high cyclin B1 expression on 3 and 5-year OS. Statistically significant effect of cyclin B1 expression on 3-year OS was observed in patients with stage I-III (OR 0.25; 95\% CI 0.11, $0.58 ; P=0.001$ ). For the effect of cyclin B1 expression on 5-year OS, significant results were found in subgroups of I-III (OR 0.23; 95\% CI $0.11,0.48 ; P<0.0001)$ and TNM stage $P<0.05$ (OR $0.32 ; 95 \%$ CI $0.13,0.76 ; P=0.010)$. In addition, there was good homogeneity among the studies in the subgroup of stage I-III for no significant heterogeneity was found, thus FEM was used to evaluate the pooled effects. No significant association was found in the subgroups of stage I-IV, TNM stage $P<0.05$ and Cut-off value $=10 \%$ or $\leq$ 5\% (Table 3).

We performed sensitivity analysis to examine the stability of the combined results of overall survival and to identify the source of heterogeneity by omitting any single study. Sensitivity analysis showed that the combined OR of 3-year OS of all types of cancer had high stability by omitting each single study, for that the pooled ORs ranged from 0.60 [95\% CI $0.26,1.39]$ after omitting the study of Fang et al. 2015 [18] to 0.62 [95\% CI 0.27, 1.45] after omitting the study of Yasuda et al. 2002 [17]. However, for 5-year OS of all types of cancer, three particular studies, Fang et al. 2015 [18], Grabsch et al. 2004 [19] and Kim et al. 2007 [16], significantly affected the pooled results. The pooled ORs respectively changed from $0.56[95 \%$ CI $0.30,1.06]$ to 0.45 [95\% CI $0.25,0.81], 0.48$ [95\% CI $0.25,0.93]$ and 0.50 [95\% CI $0.26,0.95]$ after excluding each of them from the meta-analysis seriatim. The pooled results of 3 and 5-year OS of esophageal cancer and colorectal cancer had high stability as well. No single study was found significantly affecting heterogeneity between studies.

The funnel plots showed no obvious evidence of publication bias with regard to the effects on 3 and 5-year OS (Figures 7 and 8).

\section{DISCUSSION AND CONCLUSIONS}

It has been implicated that high expression of cyclin B1, to a certain extent, may impede the autogenous controlling of cell growth and lead to a malignant phenotype [28]. The adjustion of cell cycle progression is strongly necessary for cells to keep gene integration which is very critical for cell survival. According to current research, cyclin B1 is one of a family of proteins varying in their expression levels during the cell proliferation cycle [29-32]. Cyclin B1 has various roles in cell proliferation cycle, including cell differentiation, cell apoptosis, and the (tumor cell) distant metastasis [33-37]. Increasing

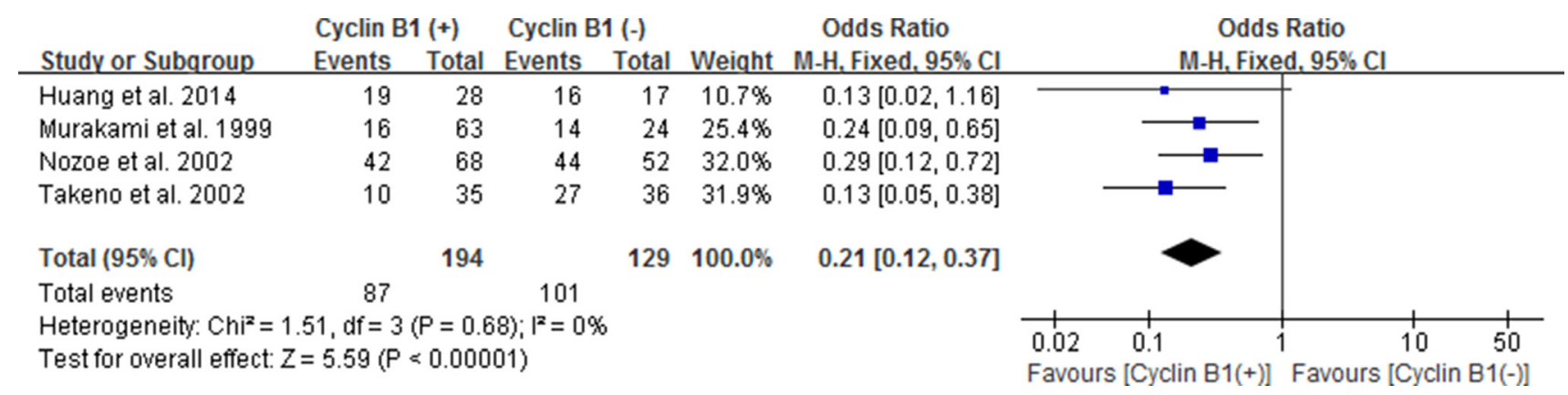

Figure 4: Forest plot for the association between positive/high expression of cyclin B1 and 3-year overall survival (OS) of esophageal cancer.

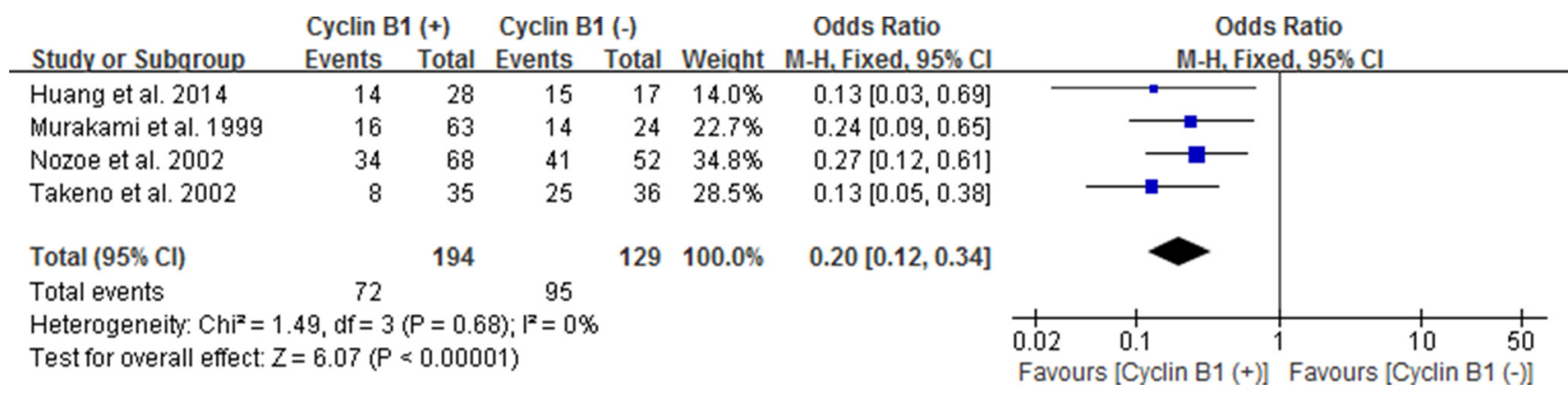

Figure 5: Forest plot for the association between positive/high expression of cyclin B1 and 5-year overall survival (OS) of esophageal cancer. 
Table 2: The association between Cyclin B1 and clinical features

\begin{tabular}{lccccccccc}
\hline Clinical features & $\begin{array}{c}\text { No. of } \\
\text { studies }\end{array}$ & $\begin{array}{c}\text { No. of } \\
\text { patients }\end{array}$ & \multicolumn{3}{c}{ Pooled results } & \multicolumn{3}{c}{ Heterogeneity } \\
\cline { 5 - 9 } & & & OR & $\mathbf{9 5 \% ~ C I ~}$ & P value & $\mathbf{I}^{2}$ & P value & $\begin{array}{c}\text { Analytical effect } \\
\text { model }\end{array}$ \\
\hline Age & 5 & 1090 & 0.72 & $0.50,1.02$ & 0.07 & $0 \%$ & 0.41 & FEM \\
Gender & 6 & 817 & 1.03 & $0.67,1.57$ & 0.91 & $0 \%$ & 0.73 & FEM \\
Size of tumor & 3 & 832 & 0.60 & $0.38,0.93$ & 0.02 & $0 \%$ & 0.73 & FEM \\
Histologic type & & & & & & & & \\
Well vs. Moderate & 6 & 669 & 1.25 & $0.80,1.93$ & 0.32 & $0 \%$ & 0.49 & FEM \\
Well vs. Poor & 6 & 812 & 1.40 & $0.44,4.44$ & 0.57 & $75 \%$ & 0.001 & REM \\
Moderate vs. Poor & 6 & 1011 & 0.85 & $0.43,1.69$ & 0.64 & $58 \%$ & 0.04 & REM \\
Pathologic T & 7 & 1402 & 0.74 & $0.41,1.34$ & 0.32 & $68 \%$ & 0.005 & REM \\
Pathologic N & 8 & 1413 & 0.71 & $0.40,1.25$ & 0.23 & $69 \%$ & 0.002 & REM \\
Metastasis & 4 & 807 & 0.30 & $0.13,0.71$ & 0.006 & $32 \%$ & 0.22 & FEM \\
Blood vessel invasion & 6 & 1315 & 0.90 & $0.43,1.86$ & 0.77 & $70 \%$ & 0.006 & REM \\
Lymphatic vessel invasion & 6 & 1319 & 0.85 & $0.43,1.67$ & 0.64 & $73 \%$ & 0.002 & REM \\
TNM stage & 7 & 1802 & 0.67 & $0.29,1.54$ & 0.34 & $86 \%$ & $<0.00001$ & REM \\
\hline
\end{tabular}

REM, random-effect model; FEM, fixed effects model; OR, odds ratio; CI, confidence intervals.

Table 3: The pooled results of subgroups for the association between Cyclin B1 and 3-year OS or 5-year OS

\begin{tabular}{|c|c|c|c|c|c|c|c|}
\hline \multirow[t]{2}{*}{ Subgroups } & \multirow[t]{2}{*}{ Number of studies } & \multicolumn{3}{|c|}{ Pooled results (3-year OS) } & \multicolumn{3}{|c|}{ Pooled results (5-year OS) } \\
\hline & & OR & $95 \% \mathrm{CI}$ & $P$ value & OR & $95 \% \mathrm{CI}$ & $P$ value \\
\hline \multicolumn{8}{|c|}{ Clinical stage } \\
\hline I-IV & 7 & 0.93 & $0.40,2.17$ & 0.86 & 0.77 & $0.32,1.88$ & 0.56 \\
\hline I-III & 2 & 0.25 & $0.11,0.58$ & 0.001 & 0.23 & $0.11,0.48$ & $<0.0001$ \\
\hline \multicolumn{8}{|c|}{$P$ value of TNM stage } \\
\hline$<0.05$ & 4 & 0.34 & $0.05,2.30$ & 0.27 & 0.32 & $0.13,0.76$ & 0.010 \\
\hline$>0.05$ & 4 & 0.59 & $0.24,1.46$ & 0.25 & 0.49 & $0.13,1.91$ & 0.30 \\
\hline \multicolumn{8}{|c|}{ Cut-off value } \\
\hline $10 \%$ & 5 & 0.87 & $0.31,2.41$ & 0.78 & 0.59 & $0.31,1.12$ & 0.11 \\
\hline$\leq 5 \%$ & 4 & 1.25 & $0.35,4.51$ & 0.73 & 1.43 & $0.20,10.38$ & 0.72 \\
\hline
\end{tabular}

OS, overall survival; OR, odds ratio; CI, confidence intervals.

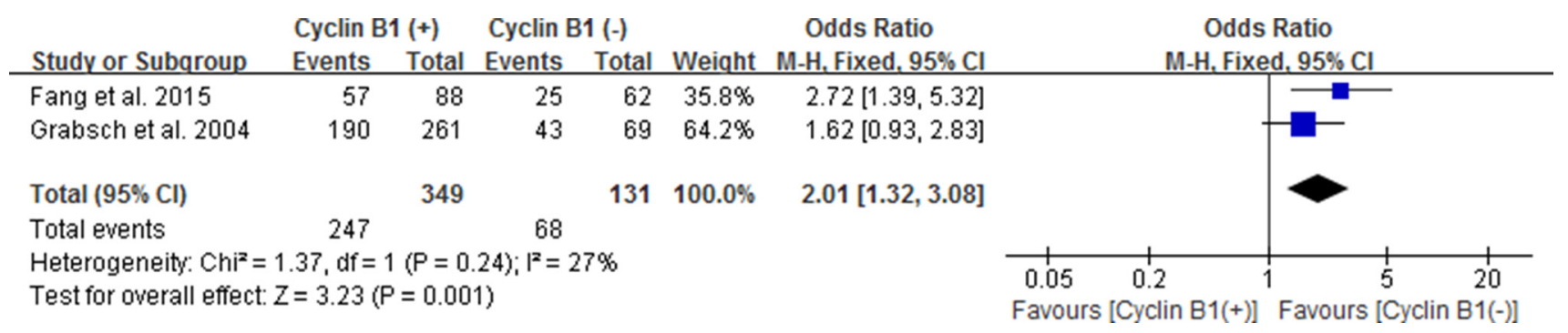

Figure 6: Forest plot for the association between positive/high expression of cyclin B1 and 5-year overall survival (OS) of colorectal cancer. 
proofs have indicated that the important protein was high or over expressed in laryngeal cancer [12], prostate cancer [9], pancreatic carcinoma [10], lung carcinoma [11], breast carcinoma [8], hepatocellular cancer [13], esophageal cancer, gastric cancer and colorectal cancer $[15,20,23,24]$. Murakami $H$ et al. reported that the cyclin B1 prevalently expressed in patients with tumor deeper invasion than superficial invasion [25]. Song Y.M et al. suggested that the protein result in tumor distant metastasis likely via accelerate a transition of epithelial to mesenchyma [29]. The study from Wang A. et al. showed much higher expression of the protein in human colorectal carcinomas than did the non-neoplastic mucosa [26]. Besides, previous studies have also compared the

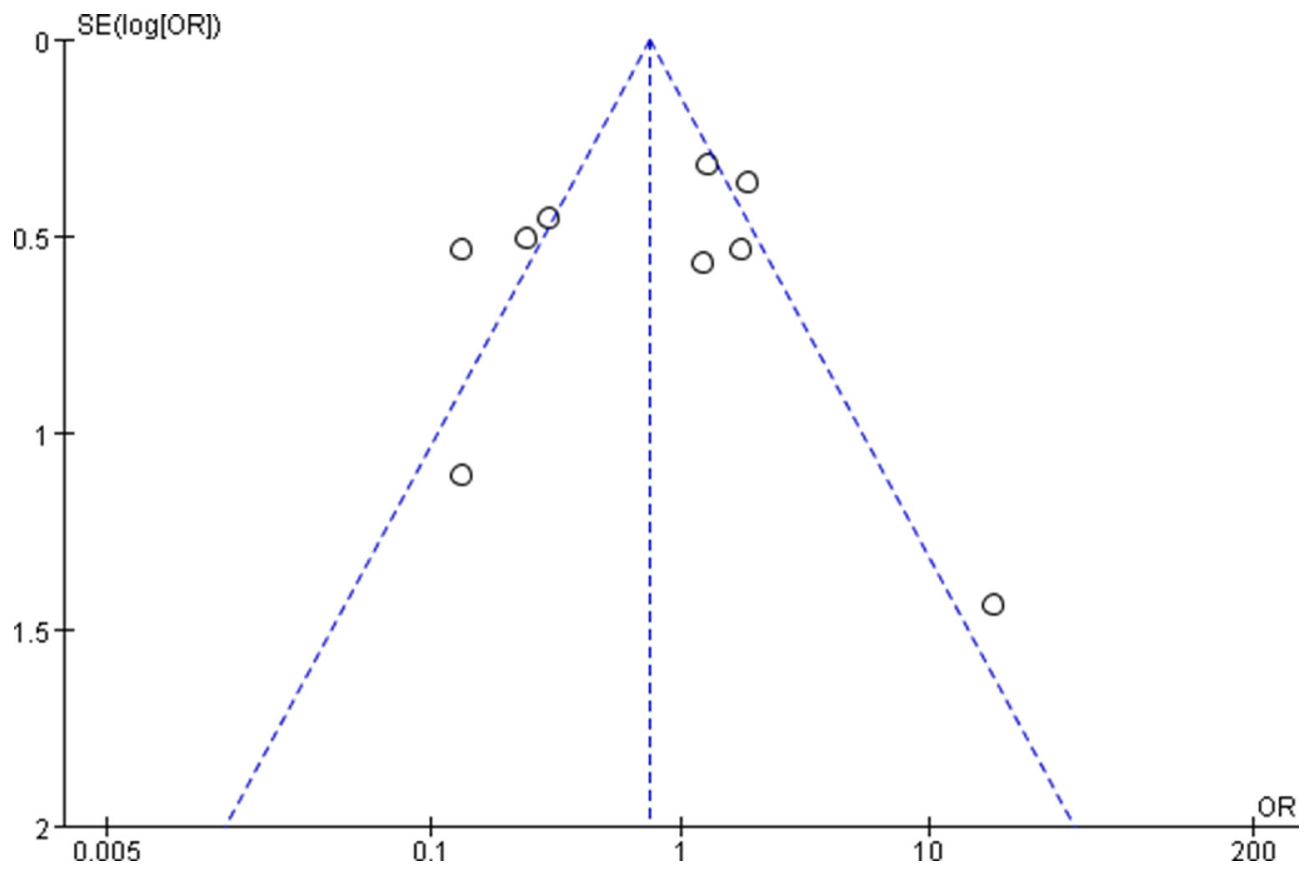

Figure 7: Funnel plots for detecting publication bias of the association between positive/high expression of cyclin B1 and 3-year overall survival (OS) of overall types of cancer.

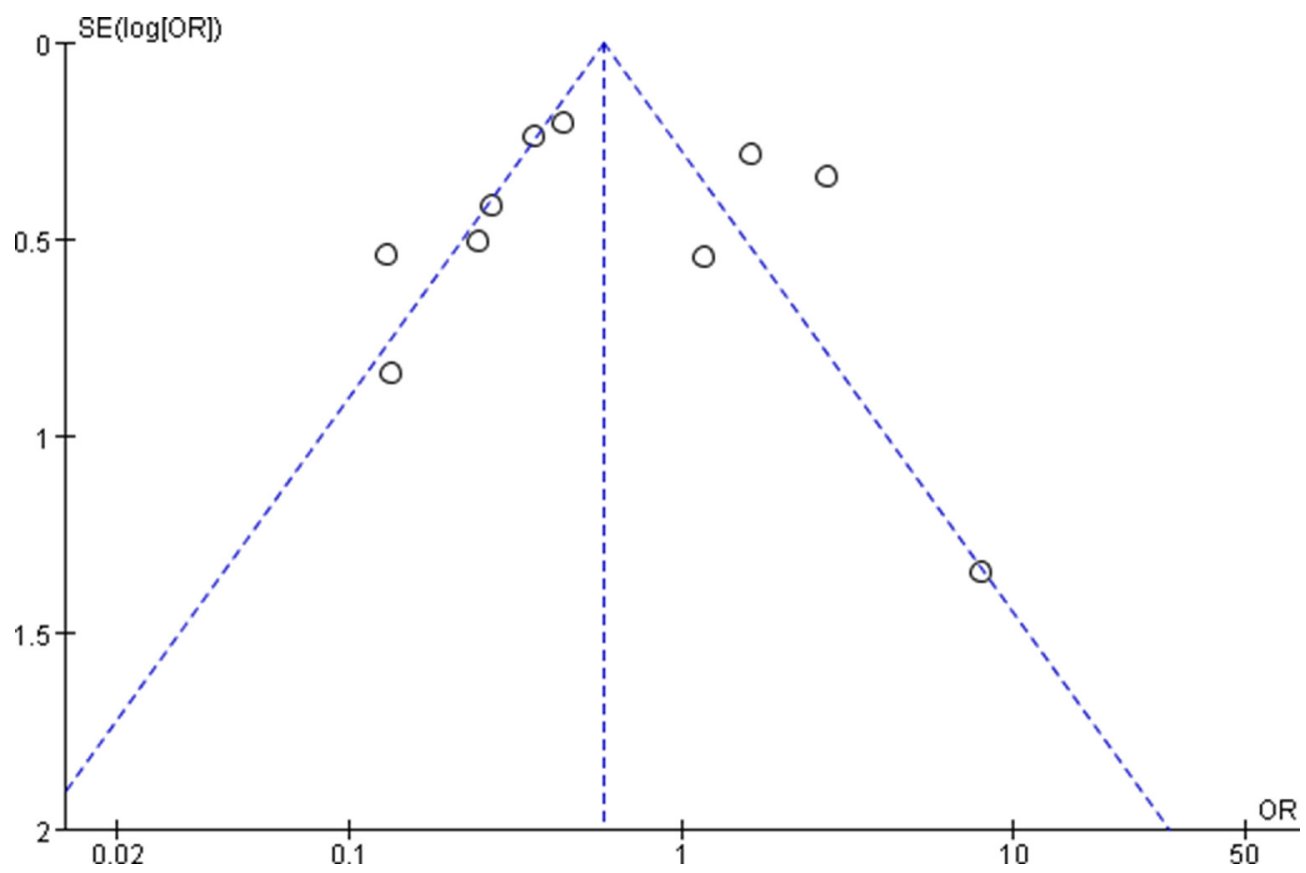

Figure 8: Funnel plots for detecting publication bias of the association between positive/high expression of cyclin B1 and 5-year overall survival (OS) of overall types of cancer. 
different significance of positive cyclin B1 expression in nuclear and cytoplasm, and testified that the protein expression, especially nuclear dominant expression, can be significant as a prognostic indicator in esophageal cancer [24]. However, the detailed role and mechanism of cyclin B1 in prognosis of cancer patients was not clear. What's more, their results still remained inconsistent. The findings from Fang Y. et al. suggested that cyclin B1 could control the invasion and distant metastasis of colorectal cancer cells [18], which was opposite to with other studies [14-16, 20]. Besides, according to Grabsch's results, though this protein was frequently and early expression in malignancies, it did not predict the prognosis and recurrence risk for patients [19]. Considering all kinds of discrepancies above, further study was needed to unitize the different voice.

We perform the present analysis to demonstrate the significance of cyclin B1 expression for the survival of patients with digestive malignancies. Exceptionally, results of the present analysis did not remarkable support the consequence that high or elevated cyclin B1 expression was significantly correlated with the prognosis in all types of digestive cancer. However, surprisingly, we found the prominent pertinence between the high/over-expression of cyclin B1 and esophageal cancer or colorectal cancer. In esophageal cancer, cyclin B1 positive/high expression had an evident association with both 3 -year OS (OR 0.21, 95\% CI 0.12-0.37; $P<0.00001$ ) (Figure 4) and 5-year OS (OR 0.20, 95\% CI 0.12-0.34; $P<0.00001$ ) (Figure 5). The pooled OR was 2.01 [95\% CI 1.32-3.08; $P=0.001$ ] in colorectal cancer (Figure 6). Interestingly, though the significance was found both in esophageal cancer and colorectal cancer, it was a contrary clinical result. According to the results, patients with cyclin B1 positive/ high expression experienced a poor prognosis and low 3 or 5-year OS in esophageal cancer, but high 5-year OS in patients with colorectal cancer, which was consistent with the study of Korenaga D et al. 2002 [21]. Ye C et al. [27] came to the same conclusion in esophageal carcinoma and colonic or rectal carcinoma. The reason for this inconsistent results may be the different expression modes of cyclin B1 in different tissue types of tumor. In addition, we also estimated association between elevated cyclin B1 expression and clinicopathological features. In the overall pooled analysis, the results suggested that cyclin B1 positive/high expression was statistically correlated with size of tumor lesions (OR, 0.60; 95\% CI, 0.38, 0.93) and distant Metastasis (OR, 0.30; 95\% CI, 0.13, 0.71), but not with other clinicopathological features such as gender, grade, Pathologic T, Pathologic N, Blood vessel invasion and Histologic type in the patients with digestive cancer. According to the study of Yasuda M et al. 2002, tumors tissue in which cyclin B1 expressing were prevalent in gerontal patients, in better differentiation and swellinggrowth tumors, but was lower expression in poorly differentiated and invasive-growth tumor. The subgroup analysis they performed in study indicated that tumor histological type was one of remarkable factors relating to cyclin B1 protein expression [17]. In subgroup analysis of 3 and 5-year OS, the results indicated that positive/high cyclin B1 expression was prominently correlated with 3 -year OS of patients with stage I-III (OR 0.25 ; $95 \%$ CI $0.11,0.58 ; P=0.001)$ and 5 -year OS of patients with stage I-III (OR 0.23; 95\% CI 0.11, 0.48; $P<0.0001)$ and TNM stage $P<0.05$ (OR $0.32 ; 95 \%$ CI $0.13,0.76 ; P=0.010$ ), but not in other subgroups. According to the results from sensitivity analysis, we found that the study from Fang et al. 2015, Grabsch et al. 2004 and Kim et al. 2007 [16, 18, 19] had significant impacts on the pooled results. When the studies above was got rid from the analysis lists, the pooled OR became 0.45 [95\% CI $0.25,0.81], 0.48$ [95\% CI $0.25,0.93]$ and 0.50 [95\% CI $0.26,0.95]$ for 5-year OS.

However, several limitations existed in thsi meta-analysis. One of the main deficiencies was the inconformity of the cut-off values (definition of positive/ high expression of cyclin B1). The cut-off values ranged from $4.6 \%$ to $20 \%$, but the majority of studies used $10 \%$. The cut-off values may directly affect the results of analysis. In the study of Huang TY et al. 2014 [22], they classified the $-/+$ to negative, $++/+++$ to positive to generate the survival curves, but Murakami $\mathrm{H}$ et al. regarded $1+$ and $2+$ as positive [25]. Besides, Takeno $S$ et al. 2002 [23] suggested that elevated cyclin B1 expression was correlated remarkablely with a poor prognosis in patients with esophageal cancer when the cut-off value for positivity was set at 20\% $(P<0.0001)$. Indeed, cut-off values of $>30 \%,>40 \%$, and $>50 \%$ also were correlated significantly with patient outcome, with values of $P<0.0001$. However, the $10 \%$ cut-off value did not reach statistical significance $(P=0.075)$ [23]. The second deficiency was the extensive changes of patients' clinical stages, because the outcome or survival of cancer patients was affected by their clinical stages to a great degree. Indeed, according to our results, patients with stage I-III who had high/positive cyclin B1 expression had poor 3 or 5-year OS. Besides, we also found that distant metastasis was significantly associated with positive/high expression of cyclin B1, but to combine the results, we regarded stage 0-III as no metastasis and IV as distant metastasis in study of Murakami H et al. 1999 [25]. In addition, in the study of Nozoe T et al. 2002 [24], because of only 1, 3 and 5 -year survival rate were given, we converted them to the survival number of patients to make the pooled analysis, which may lead to some bias. Finally, the prognosis were also affected by many of other composite factors, such as tumor histological type, accepting adjuvant therapy or not, patients age, tumor size and venous involvement or not, which should also be taken into consideration.

Considering the limitations above, further research with different clinical stages should be designed to clear the association between positive/high expression of cyclin B1 and prognosis of patients. In addition, further 
studies should demonstrate which one should be regarded as the optimal cut-off value of cyclin B1 expression for predicting the prognosis of patients with digestive cancer.

In conclusion, according to the present analysis, we could cautiously come to the conclusion that positive/high expression of cyclin B1 may associate with poor prognosis in patients with esophageal cancer, but better prognosis in patients with colorectal cancer, with consideration of the evident statistical significance. In addition, cyclin B1 expression may be associated with size of tumor and distant metastasis. Elevated cyclin B1 expression may be used as one of prognostic indicators for early identification of poor prognosis for patients with digestive cancer.

\section{MATERIALS AND METHODS}

\section{Criteria for considering studies of this meta- analysis}

The including criteria: (1) Immumohistochemical staining of cyclin B1 with surgical specimens; (2) Included people with a pathological diagnosis of $\mathrm{EC}, \mathrm{GC}$ or CRC; (3) All of randomized, controlled trials (RCTs), observational prospective or retrospective studies were included; (4) Definition of positive/high expression of cyclin B1 was reported; (5) The outcomes including overall survival was reported; (6) Sufficient data (number of cyclin B1 positive patients and their characteristics) were provided.

Excluding criteria: (1) Studies about animals; (2) Non-research studies such as expert opinions, letters, editorials, reviews and case reports; (3) Studies whose participants complicated with other primary tumors; (4) Studies without sufficient data; (5) The definition of positive/high expression of cyclin B1 (cut-off value) was not given or did not meet our including criteria.

\section{Types of objective measures}

The primary objective was the association between cyclin B1 high/positive expression and 3-year OS or 5-year OS.

The secondary objective was the association between cyclin B1 high/positive expression and clinical features including Age, Gender, Size of tumor, Histologic type, Pathologic T, Pathologic N, distant metastasis, Blood vessel invasion, Lymphatic vessel invasion and clinical TNM stage.

\section{Search strategy}

Database of PubMed, EMBASE, Cochrane Library and Web of Science were searched online to January, 2017. Our searching terms and procedures were as follows: (1)“cyclin B1"; (2) "esophageal cancer" OR “esophageal carcinoma” OR “esophageal tumor”; (3) "gastric cancer" OR "gastric carcinoma" OR "gastric tumor"; (4) "colorectal cancer" OR "colorectal carcinoma" OR “colorectal tumor"; (5) "prognosis" OR "survival” OR “outcome”. Search strategy was: 1 AND (2 OR 3 OR 4) AND 5. Two researchers independently screened the titles and abstracts of each study. Then full text will be obtained for further evaluation if one get our including criteria.

\section{Quality assessment}

We used the 9-star Newcastle-Ottawa Scale (NOS) [38] to assess the quality of all included studies, and the total scores of each study were displayed in the characteristics table (Table 1). Three aspects of NOS of evaluation, including selection, comparability, and outcome between the case group and control group were offered for scoring. We consider studies with the scores $\geq 6$ as high-quality.

\section{Data extraction}

Data for the analysis were extracted independently by two reviewers. When there was disagreement during the selection process, it was resolved by discussion. The extracted contents including study demographics, published years, country, tumor location, treatment, follow-up time, definition of positive/high expression, age, gender, size of tumor, histologic type, pathologic T, pathologic $\mathrm{N}$, distant metastasis, blood vessel invasion, lymphatic vessel invasion and clinical stage were extracted using a standardized form. Data collected were input into RevMan 5.2 software for analysis [39].

\section{Statistical analysis}

In the present analysis, the prognostic value of cyclin B1 expression in patients with digestive cancer was measured by estimating the Odds Ratio (OR) between high/positive expression of cyclin B1 groups and low/ negative expression of cyclin B1 groups. The associated 95\% Confidence Intervals (CI) were also measured. The heterogeneity between studies was evaluated with $P$ value and $I^{2} . I^{2} \geq 50 \%$ or $P \leq 0.10$ was deemed to represent significant heterogeneity $[40,41]$, and pooled OR was estimated using a Random-effect model. On the contrary, if statistical study heterogeneity was not observed $\left(\mathrm{I}^{2} \leq 50 \%\right.$ and $\left.P \geq 0.10\right)$, a fixed effects model was used. The association between the expression of cyclin B1 and clinical characteristics of patients was evaluated in the same way. For the pooled OR estimates of OS, we performed subgroup analysis by Clinical stage (I-IV vs. I-III), $P$ value of TNM stage $(P<0.05$ vs. $P>0.05)$ and Cut-off value $(10 \%$ vs. $\leq 5 \%)$. Besides, we performed sensitivity analysis to examine the stability of the combined results and to identify the source of heterogeneity. Finally, Begg's and Egger's test were used to assess the publication bias. No obvious publication 
bias was detected, if the shape of funnel plots revealed no obvious asymmetry. All statistical analyses were performed using standard statistical procedures provided in RevMan 5.2 [39].

\section{ACKNOWLEDGMENTS AND FUNDING}

Wen-Ping Lian contributed to the study design, data analysis and quality assessment. Lei Cao contributed to the literature search; Yong Wen and Yong-hong Wang contributed to the manuscript writing. There is no funding for this work.

\section{CONFLICTS OF INTEREST}

The authors declared no interests.

\section{REFERENCES}

1. Siegel RL, Miller KD, Jemal A. Cancer statistics, 2015. CA Cancer J Clin. 2015; 65:5-29.

2. Cheng L, Eng C, Nieman LZ, Kapadia AS, Du XL. Trends in Colorectal Cancer Incidence by Anatomic Site and Disease Stage in the United States From 1976 to 2005. Am J Clin Oncol. 2011; 34:573-580.

3. Ferlay J, Soerjomataram I, Dikshit R, Eser S, Mathers C, Rebelo M, Parkin DM, Forman D, Bray F. Cancer incidence and mortality worldwide: Sources, methods and major patterns in GLOBOCAN 2012. Int J Cancer. 2015; 136:E359-86.

4. Kanavos P, Schurer W. The dynamics of colorectal cancer management in 17 countries. Eur J Health Econ. 2010 (Suppl 1); 10:S115-29.

5. Torre LA, Bray F, Siegel RL, Ferlay J, Lortet-Tieulent J, Jemal A. Global cancer statistics, 2012. CA Cancer J Clin. 2015; 65:87-108.

6. Aranda E, Aparicio J, Alonso V, Garcia-Albeniz X, GarciaAlfonso P, Salazar R, Valladares M, Vera R, Vieitez JM, Garcia-Carbonero R. SEOM clinical guidelines for diagnosis and treatment of metastatic colorectal cancer 2015. Clin Transl Oncol. 2015; 17:972-81.

7. National Cancer Institute. SEER Stat Fact Sheets: Colon and Rectum Cancer. 2011. http://seer.cancer.gov/statfacts/ html/colorect.html. Accessed 12 Aug 2014.

8. Agarwal R, Gonzalez-Angulo AM, Myhre S, Carey M, Lee JS, Overgaard J, Alsner J, Stemke-Hale K, Lluch A, Neve RM, Kuo WL, Sorlie T, Sahin A, et al. Integrative analysis of cyclin protein levels identifies cyclin b1 as a classifier and predictor of outcomes in breast cancer. Clin Cancer Res. 2009; 15:3654-62.

9. Mashal RD, Lester S, Corless C, Richie JP, Chandra R, Propert KJ, Dutta A. Expression of cell cycle-regulated proteins in prostate cancer. Cancer Res. 1996; 56:4159-4163.

10. Zhou L, Li J, Zhao YP, Cui QC, Zhou WX, Guo JC, You L, $\mathrm{Wu}$ WM, Zhang TP. The prognostic value of Cyclin B1 in pancreatic cancer. Med Oncol. 2014; 31:107.
11. Soria JC, Jang SJ, Khuri FR, Hassan K, Liu D, Hong WK, Mao L. Overexpression of cyclin B1 in early-stage nonsmall cell lung cancer and its clinical implication. Cancer Res. 2000; 60:4000-4004.

12. Dong Y, Sui L, Watanabe Y, Sugimoto K, Tokuda M. Clinical relevance of cyclin B1 overexpression in laryngeal squamous cell carcinoma. Cancer Lett. 2002; 177:13-19.

13. Weng L, Du J, Zhou Q, Cheng B, Li J, Zhang D, Ling C. Identification of cyclin B1 and Sec62 as biomarkers for recurrence in patients with HBV-related hepatocellular carcinoma after surgical resection. Mol Cancer. 2012; 11:39.

14. Begnami MD, Fregnani JH, Nonogaki S, Soares FA. Evaluation of cell cycle protein expression in gastric cancer: cyclin B1 expression and its prognostic implication. Hum Pathol. 2010; 41:1120-1127.

15. Li YZ, Zhao P. [Expressions of cyclinB1, FHIT and Ki-67 in 336 gastric carcinoma patients and their clinicopathologic significance]. [Article in Chinese]. Zhonghua Yi Xue Za Zhi. 2009; 89:2337-41.

16. Kim DH. Prognostic implications of cyclin b1, p34cdc2, p27(Kip1) and p53 expression in gastric cancer. Yonsei Med J. 2007; 48:694-700.

17. Yasuda M, Takesue F, Inutsuka S, Honda M, Nozoe $\mathrm{T}$, Korenaga D. Overexpression of cyclin B1 in gastric cancer and its clinicopathological significance: an immunohistological study. J Cancer Res Clin Oncol. 2002; 128:412-16.

18. Fang Y, Liang X, Jiang W, Li J, Xu J, Cai X. Cyclin b1 suppresses colorectal cancer invasion and metastasis by regulating e-cadherin. PLoS One. 2015; 10:e0126875.

19. Grabsch H, Lickvers K, Hansen O, Takeno S, Willers R, Stock W, Gabbert HE, Mueller W. Prognostic value of cyclin B1 protein expression in colorectal cancer. American Am J Clin Pathol. 2004; 122:511-516.

20. Li JQ, Kubo A, Wu F, Usuki H, Fujita J, Bandoh S, Masaki T, Saoo K, Takeuchi H, Kobayashi S, Imaida K, Maeta H, Ishida $\mathrm{T}$, et al. Cyclin B1, unlike cyclin G1, increases significantly during colorectal carcinogenesis and during later metastasis to lymph nodes. Int J Oncol. 2003; 22:1101-1110.

21. Korenaga D, Takesue F, Yasuda M, Honda M, Nozoe $\mathrm{T}$, Inutsuka $\mathrm{S}$. The relationship between cyclin B1 overexpression and lymph node metastasis in human colorectal cancer. Surgery. 2002 (Suppl); 131:S114-20.

22. Huang T, Chen S, Han H, Li H, Huang Z, Zhang J, Yin Q, Wang X, Ma X, Dai P, Duan D, Zou F, Chen X. Expression of Hsp90 alpha and cyclin B1 were related to prognosis of esophageal squamous cell carcinoma and keratin pearl formation. Int J Clin Exp Pathol. 2014; 7:1544-52.

23. Takeno S, Noguchi T, Kikuchi R, Uchida Y, Yokoyama S, Müller W. Prognostic value of cyclin B1 in patients with esophageal squamous cell carcinoma. Cancer. 2002; 94:2874-2881.

24. Nozoe T, Korenaga D, Kabashima A, Ohga T, Saeki H, Sugimachi K. Significance of cyclin B1 expression as an 
independent prognostic indicator of patients with squamous cell carcinoma of the esophagus. Clin Cancer Res. 2002; 8:817-22.

25. Murakami H, Furihata M, Ohtsuki Y, Ogoshi S. Determination of the prognostic significance of cyclin B1 overexpression in patients with esophageal squamous cell carcinoma. Virchows Arch. 1999; 434:153-58.

26. Wang A, Yoshimi $\mathrm{N}$, Ino $\mathrm{N}$, Tanaka $\mathrm{T}$, Mori $\mathrm{H}$. Overexpression of cyclin B1 in human colorectal cancers. J Cancer Res Clin Oncol. 1997; 123:124-7.

27. Ye C, Wang J, Wu P, Li X, Chai Y. Prognostic role of cyclin B1 in solid tumors: a meta-analysis. Oncotarget. 2017; 8:2224-32. https://doi.org/10.18632/oncotarget.13653.

28. Egloff AM, Vella LA, Finn OJ. Cyclin B1 and other cyclins as tumor antigens in immunosurveillance and immunotherapy of cancer. Cancer Res. 2006; 66:6-9.

29. Song Y, Zhao C, Dong L, Fu M, Xue L, Huang Z, Tong T, Zhou Z, Chen A, Yang Z, Lu N, Zhan Q. Overexpression of cyclin B1 in human esophageal squamous cell carcinoma cells induces tumor cell invasive growth and metastasis. Carcinogenesis. 2008; 29:307-315.

30. Matthess Y, Raab M, Sanhaji M, Lavrik IN, Strebhardt K. Cdk1/cyclin B1 controls Fas-mediated apoptosis by regulating caspase- 8 activity. Mol Cell Biol. 2010; 30:5726-5740.

31. Kedinger V, Meulle A, Zounib O, Bonnet ME, Gossart JB, Benoit E, Messmer M, Shankaranarayanan P, Behr JP, Erbacher P, Bolcato-Bellemin AL. Sticky siRNAs targeting survivin and cyclin B1 exert an antitumoral effect on melanoma subcutaneous xenografts and lung metastases. BMC Cancer. 2013; 13:338.

32. Bonnet ME, Gossart JB, Benoit E, Messmer M, Zounib O, Moreau V, Behr JP, Lenne-Samuel N, Kedinger V, Meulle A, Erbacher P, Bolcato-Bellemin AL. Systemic delivery of sticky siRNAs targeting the cell cycle for lung tumor metastasis inhibition. J Control Release. 2013; 170:183-90.

33. Patil GB, Hallikeri KS, Balappanavar AY, Hongal SG, Sanjaya PR, Sagari SG. Cyclin B1 overexpression in conventional oral squamous cell carcinoma and verrucous
carcinoma-A correlation with clinicopathological features. Medicina Oral Patologia Oral Y Cirugia Bucal. Med Oral Patol Oral Cir Bucal. 2013; 18:e585-90.

34. Ou YW, Ma L, Ma L, Huang Z, Zhou W, Zhao C, Zhang B, Song Y, Yu C, Zhan Q. Overexpression of cyclin B1 antagonizes chemotherapeutic-induced apoptosis through PTEN/Akt pathway in human esophageal squamous cell carcinoma cells. Cancer Biol Ther. 2013; 14:45-55.

35. Nakayama Y, Yamaguchi N. Role of cyclin B1 levels in DNA damage and DNA damage-induced senescence. Int Rev Cell Mol Biol. 2013; 305:303-37.

36. Gao SY, Li J, Qu XY, Zhu N, Ji YB. Downregulation of Cdk1 and cyclinB1 expression contributes to oridonininduced cell cycle arrest at $\mathrm{G} 2 / \mathrm{M}$ phase and growth inhibition in SGC-7901 gastric cancer cells. Asian Pac J Cancer Prev. 2014; 15:6437-41.

37. Chae SW, Sohn JH, Kim DH, Choi YJ, Park YL, Kim K, Cho YH, Pyo JS, Kim JH. Overexpressions of Cyclin B1, cdc2, p16 and p53 in human breast cancer: the clinicopathologic correlations and prognostic implications. Yonsei Med J. 2011; 52:445-53.

38. Wells GA, Shea B, Connell DO. The Newcastle-Ottawa Scale (NOS) for Assessing the Quality of Nonrandomized Studies in Meta-analysis. Ottawa, Canada: Department of Epidemiology and Community Medicine, University of Ottawa. 2010.

39. Review Manager (RevMan) [Computer Program]. Version 5.2. Copenhagen: The Nordic Cochrane Centre, The Cochrane Collaboration, 2012.

40. Higgins JPT, Green S (editors). Cochrane Handbook for Systematic Reviews of Interventions Version 5.1.0 [updated March 2011]. The Cochrane Collaboration, 2011. Available from www.handbook.cochrane.org (18 March 2014, date last accessed).

41. University of York Centre for Reviews and Dissemination. Systematic Reviews: CRD's Guidance for Undertaking Reviews in Health Care. York: CRD, University of York. 2009. 